\title{
(التشخيص في شعر غازي القصيبي) Diagnosis in Ghazi Al-Qosaibi poetry
}

\author{
إعداد \\ د/ سعيد هادي سعد القحطاني \\ جامعة أم القرى \\ الكلية الجامعية بالليث - قسم اللغة العربية \\ منطقة مكة المكرمة \\ عنوان المراسلة \\ ايميل :

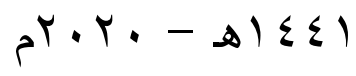




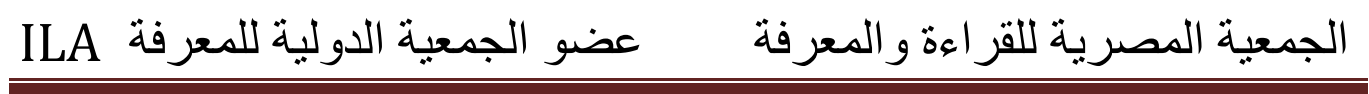




\section{ILA الجمعية المصرية للقراءة والمعرفة عضو الجمعية الدولية للمعرفة}

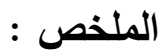

كانت ملكة التشخيص عند الثاعر غازي القصيبي قد ظهرت بشكلي جلي، مما أتاح للباحث دراستها والغوص في عالمها، فقد استخدم الثاعر غازي القصيبي ظاهرة التشخيص كثيراً

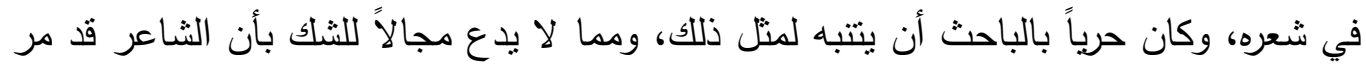

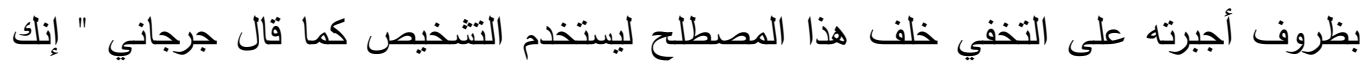

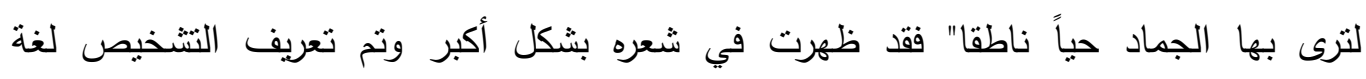

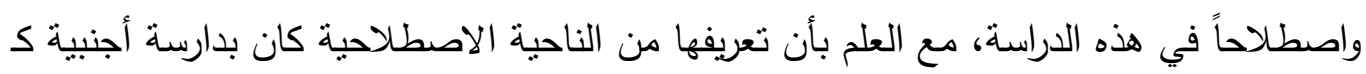
-تثارلتن - وبذلك تمت دراسة هذا المصطلح على مبدأ المقايسة على ما جاء في نراثنا النقدي

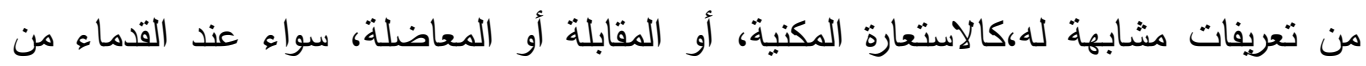
العرب أو ممن سبق العرب من القدماء مثل أرسطو • ثم تم التطرق لحياة الثاعر غازي القصيبي.

ومن ثم قام الباحث بتطبيق هذا المصطلح على شعر غازي القصيبي من خلال الدارسة التحليلية

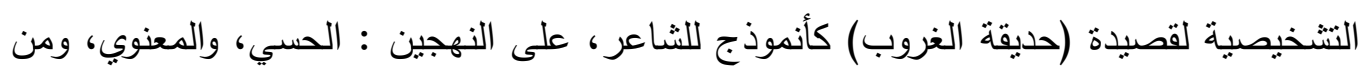
ثم الوصول لأهم النتائج والتوصيات التي وصل إليها الباحث من خلال هذه دارسته .

الكلمات المفتاحية : (الاستعارة المكنية، المعاضلة، المقابلة، الاسقاط) 


\begin{abstract}
The poet Ghazi Al-Qusaibi's diagnostic talent had evidently emerged, which enabled the researcher to study and dive into his world, the poet Ghazi Al-Qusaibi used the diagnostic phenomenon a lot in his poetry, the researcher should have taken care of such a matter, it leaves no room for doubt that, the poet has gone through circumstances that forced him to hide behind this concept in order to use the diagnostic, as Jerjani said "You can see inanimate objects alive and speaking," as the diagnosis appeared more in his poetry. Diagnostic was defined in this research, knowing that it was defined from a formal point of view in a foreign study, such as Charlton's. Thus, this concept has been studied on the principle of analogy based on what came in our critical heritage of concept similar to it, such as the metaphor, the corresponding orweak analogy either among the ancient Arabs or among those who preceded the ancient Arabs, such as Aristotle. It was subsequently written about the life of the poet.

Then the researcher applied this concept to the poetry of Ghazi Al-Qusaibi through the analytical and diagnostic study of the poem (The Garden of the Sunset) as a model for the poet, on the two approaches: tangible and intangible, and then access to the most important findings and recommendations reached by the researcher through this study.
\end{abstract}




\section{الجمعية المصرية للقر اعة و المعرفة عضو الجمعية الدولية للمعرفة ILA}

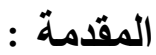

الحمد لله والصلاة والسلام على نبينا محمد وعلى أله وصحبه وسلم أما بعد فقد عمد الباحث إلى دراسة ظاهرة التشخيص في شعر غازي القصيبي ولعل هنالك أدباء قد تميزوا ببعض الظواهر الأدبية، والتي كان يجب على الباحث أن يتتبه لمنل هذه الظواهر، فقد استخدم الثاعر غازي القصيبي ظاهرة التشخيص كثيراً في شعره، وكان حرياً بالباحث أن يتببه لمنل ذلك، ومما لا يدع مجالاً للثك بأن الثاعر قد مر بظروف

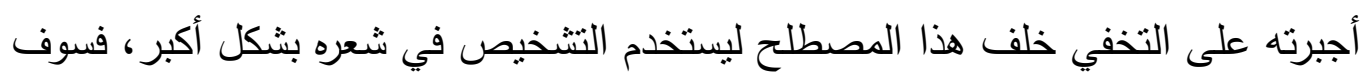
يتطرق الباحث لتعريف التشخيص لغة واصطلاحاً، مع العلم بأنه كمصطلح سوف يكون تعريفه أجنبياً، وبذلك يجب على الباحث دراسة هذا المصطلح على مبدأ المقايسة على ما لنّا

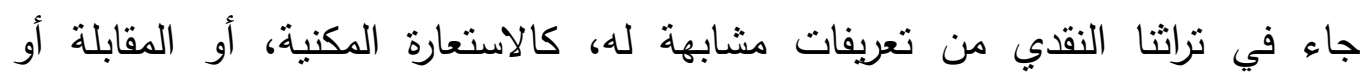
المعاضلة، سواء عند القدماء من العرب أو ممن سبق العرب مثل أرسطو. ثم التطرق نُّاء لحياة الثاعر غازي القصيبي.

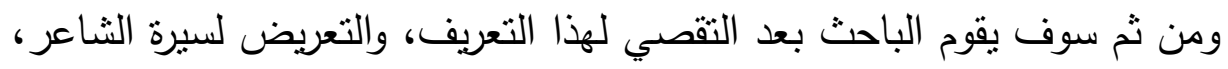
بتطبيق هذا المصطلح على شعره، والتي كانت هذه الظاهرة جلية عنده ومن ثم سوف يقوم الباحث بدارسة تحليلة تشخيصية لقصيدة (حديقة الغروب) كأنموذج للثاعر غازي القصيبي، على النهجي الحسي، والمعنوي، ومن ثم التوصل لأهم النتائج والتوصيات التي وصل إليها الباحث من خلال دراسته. أولاً : التشخيص لغة : ورد تعريف التشخيص من مادة (شخص) في معجم لسان العرب

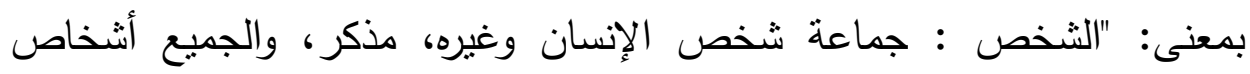

$$
\text { وخوص وشخاص، وقول عمر بن أبي ربيعة : }
$$

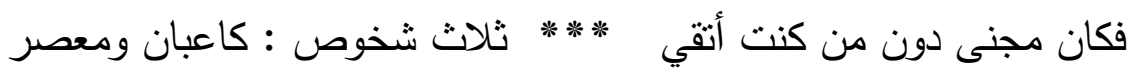

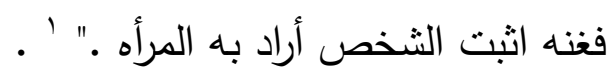

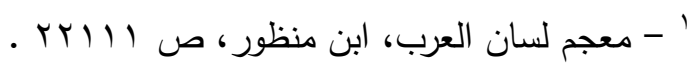




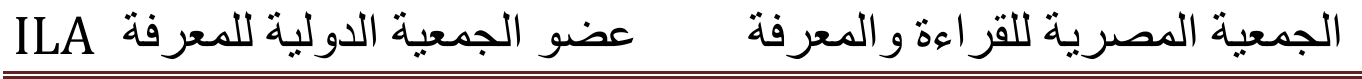

وقد ورد في معجم المصطلحات الأدبية المعاصرة كذللك بعدة معان منها : التنخيصية بمعنى : " طريقة سردية، ثقوم على نعت موضوع / شيء / وحدة مجردة /

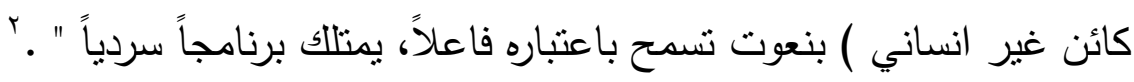

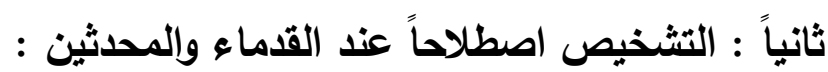
ومفاهيم التشخيص الاصطلاحية كثيرة وسوف يورد الباحث منها ما يوفي بالغرض المنشود، فهي لم ترد عند القدماء بهذا المسمى فقد بدأت بمسمى(الاستعارة)، وبالتحديد

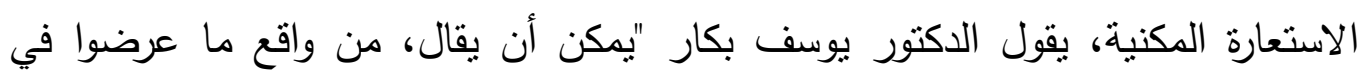

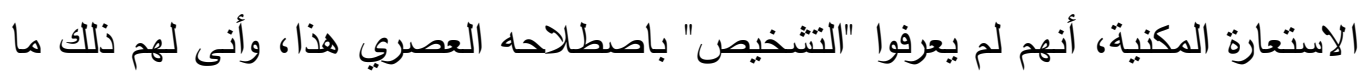
دامت هذه اللفظة نفسها غير موجودة في معاجمنا القديمة، لكنهم التفتوا معناه وداروا حول مضمونه ومفهومه، ونص بعضهم على ما يشبه تعريفه " "اّ، ويقصد بذللك الجرجاني

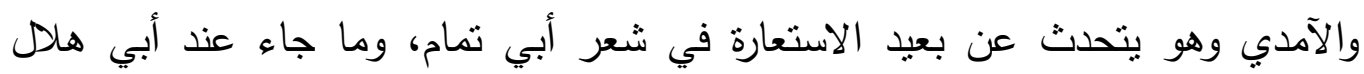

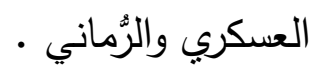

-

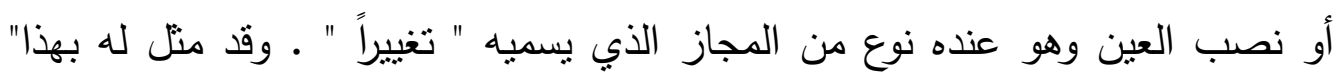
تصرخ الإذة" بأسرها "فينبغي إذا نحن نطقنا بالثيء نصب العين أن نبين ماذا نفعل وماذا يكون ، أعني أنه ينبغي أن تجعل نصب العين جميع اللاتي هن مع دلالتهن

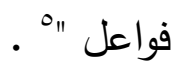

وفي معاني القرأن للفراء قول في ذللك : " جدار يريد أن ينقض يقال : كيف يريد الجدار أن ينقض ؟ وذلك من كلام العرب أن يقول الجدار يربد أن بسقط ومثله قول الله :

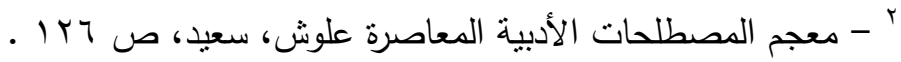

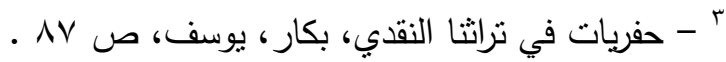

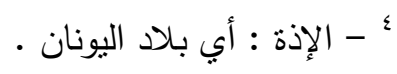

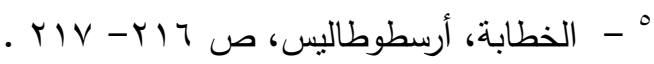




\section{الجمعية المصرية للقر اعة والمعرفة عضو الجمعية الدولية للمعرفة}

" ولما سكت عن موسى الغضب " . والغضب لا يسكت صاحبه وإنما معناه سكن، وقوله

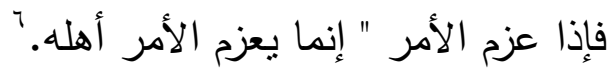
وتطرق ابن قدامة ذلك ببعض التعريض في جيد الاستعارة وقبيحها فيقول : " وقد استعمل كثير من الثعراء الفحول المجيدين أشياء من الاستعارة ليس فيها شناعة كهذه وفيها لهم معاذير إذا كان مخرجها مخرج التشبيه . فمن ذلك قول امرئ القيس :

فقلت له لما تمطلى بصلبه وأردف أعجازاً وناء بكلكل

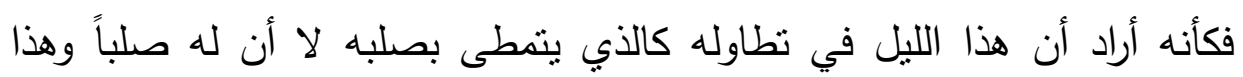

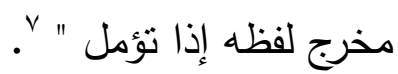
فقد تطرق قدامة لذلك في باب المعاضلة وكأنه يتكلم عن النشخيص الذي يضفي، للجماد صفات الأشخاص، فكأن الليل الإنسان وهو يتمطى فخص المشبه وهو الليل بالقربن (التمطى) الذي هو من صفات البشر . ثما جاء بعد ذلك عبد القاهر الجرجاني " ت هـ هـ فيقول عن الاستعارة وكأنه يخص بذلك التشخيص في زامننا هذا " إنك لترى بها الجماد حياً ناطقا، والأجسام الخرس الأسعاري مبينة والمعاني الخفية بادية جلية ... وإن شئت أرتلك المعاني اللطيفة التي هي من خبايا العقل كأنها قد جسِّت حتى رأتها العيون، وإن شئت لطفت الأوصاف الجثمانية حتى تعود روحانية لا تتالها إلا الظنون" ^. فنجد الجرجاني هنا قد لامس الثاهد في مصطلح التتخيص، وبذلك يقف الباحث عند هذا القدر بعد أن اتضح معنى التشخيص وعلاقته بالتوضيح والإبداع في التتبيه المقبول والذي يضفي لأعمال الأدبية قيمة رائعة تلفت انتباه المتلقي وتجذبه للاستمتاع بالقراءة، وهذا يدل عى مدى ما تتمتع به اللغة العربية من أسرار لغوية وبلاغية بمكن التعبير عنها بعدة أشنكال .

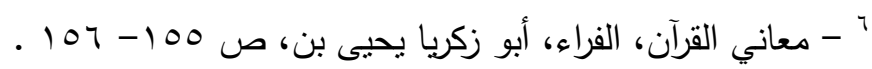

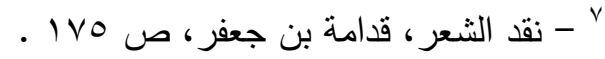

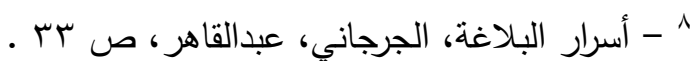


- التشخيص عند المحدثين : -

"Animation " وقد ورد تعريف التشخيص عند المحثثن بعدة معان سمي بمعنى الإحياء ولإنعاش والحيوية ـ وجاء كذلك بمعنى " Animism" بمعنى " الأروحية " أو مذهب " حيوية المادة " الذي يقوم على أن لكل ما في الكون ـ حتى الكون نفسه ـ ـروحاً أو نفساً " 9.

ويقول تشارلتن: " والاستعارة في الشعر قيمة بالغة بحيث يكاد بستحيل أن يكون الثعر شعراً بغيرها ......وما هذا ابتشخيص إلا واحد من مئات طرائق التعبير ، وأساليبه

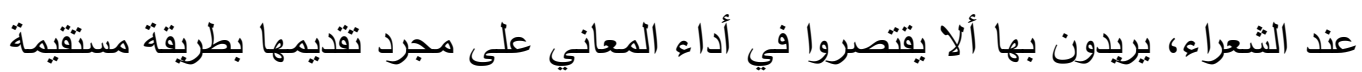
مباشرة ؛ لأنهم · إن فعلوا ـ كانوا يخاطبون العقل، ومهيتهم أن يثيروا بألفاظهم المختارة وصورهم الجيدة ' كل ما بمكنهم أن يثيروه في نفس القراء من مشاعر وذكريات" ' . ومن السمات التي جبل عليها الإنسان حبه للحياة وكرهه للموت، والثعراء يداعبون الحياة بطرائقهم وبإمكانياتهم الثعرية فيبعثون لكون ما يحط بهر بالحياة الخيالية

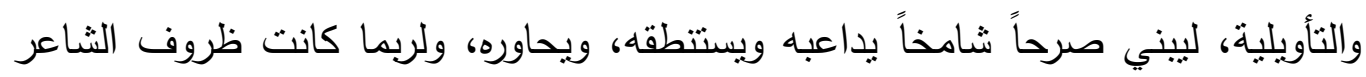
النفسية والاجتماعية والتاريخانية قد ساعدته على ذللك، فاصبح يطلق العنان لخياله، فالفنان الاصيل، رجل تحول عن الواقع، لأنه لم يستطع أن يتلاءم مع مطلب نبذ لإشباع

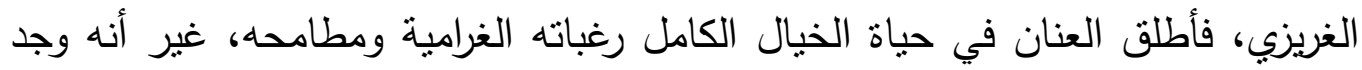
طريقاً للعودة من عالم الخيال هذا الى الواقع باستخدام (الاستعارة ـ التشخيصية) ليحاكي تطلعاته ويصوغ استعاراته بمواهبه الخاصة. والباحث قد لاحظ ما يتمتع به الثاعر غازي القصيبي من حسن الأسلوب في أعماله الأدبية وتفوقه في استخدام هذه السمة الاسلوبية والبلاغية في العديد من أعمالة

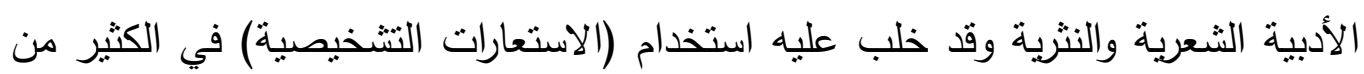

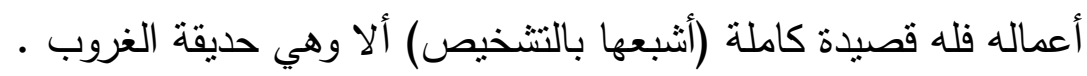

9

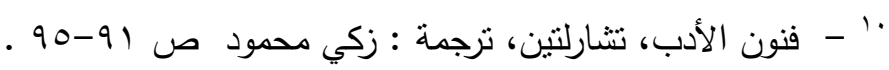




\section{الجمعية المصرية للقر اعة والمعرفة عضو الجمعية الدولية للمعرفة}

\section{من هو غازي القصيبي :}

هو الوزير والسفير والأديب والدكتور والمحامي والثاعر والإنسان : غازي عبدالرحمن القصيبي، ولد غازي القصيبي في منطقة الإحساء السعودية في ب مارس لعام • ؟ ام ، وهو أصغر أخوته ورابعهم، يصف طفولته بالكئيبة حيث أنه توفى والدته وهو رضيع، ثم تتاوب على تتشئته جدته اللينة ووالده الصارم فعاش بين قطبين متعاكسين يرى فيه غازي أن له تأثثرًا إيجابيًا على مسيرته المهنية التي أتت لاحقًا، كان متعدد المواهب مانه بين الأدب والثعر والعمل السياسي قضى حياته بين المملكة العربية السعودية والبحرين

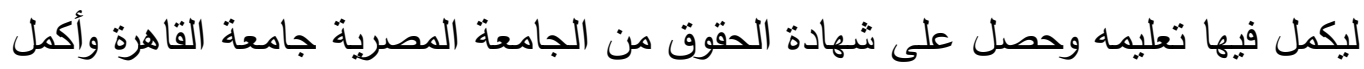
دراسته في الولايات المتحدة الامريكية للحصول على ماجستير العلاقات الدولية تقلد عدة مناصب أكاديمية كأستاذ مساعد في الجامعات السعودية ومستشار قانوني لمكاتب الوزارات الحكومية السعودية وكان له جانب اجتماعي حيث أسس جمعية لذوي الإعاقة في السعودية حصل بعدها على الدكتوراه في العلاقات الدولية من جامعة لندن البريطانية عبر

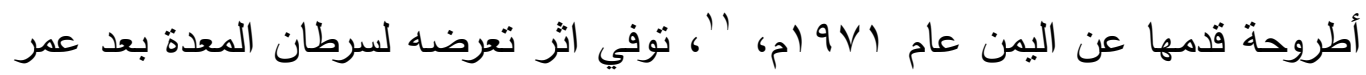

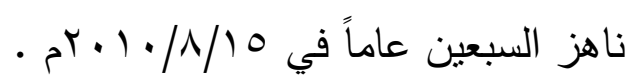
أهم ما قدم الأديب القصيبي من أعمال روائية: شقة الحرية، حياة في الإدارة، العصفورية،

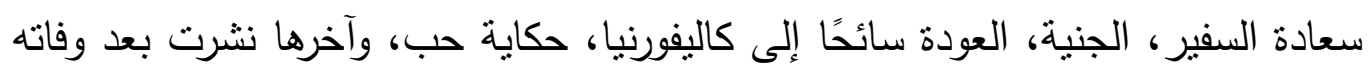
بفترة وجيزة هي أقصوصة الزهايمر، كما برز له من دواوين شعربة "الثرق والصحراء"، وديوان " حديقة الغروب "وديوان " البيت " الذي قام بتقديمه شعرًا باللغتين العربية والإنجليزية الصادر في (9V1)، وديوانه الثالث "معركة بلا راية" الذي تعرض للكثير من الاعتراض والنقد بحجة انتهاكه للدين والحكم .

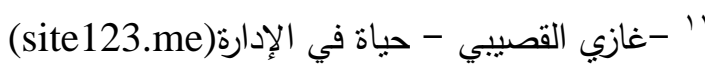
r" -ما لا تعرفه عن غازي القصيبي .. من هو سي سيرته الذاتية، إنجازاته وأقواله، معلومات عن غازي القصيبي(arageek.com) 


\section{ILA الجمعية المصرية للقر اءة والمعرفة عضو الجمعية الدولية للمعرفة}

\section{التشخيص عند غازي القصيبي : قصيدة (حليقة الغروب) أنموذجاً}

دراسة تحليلية لظاهرة ( التثخيص الحسية والمعنوية ) في قصيدة حديقة الغروب: هذه القصيدة التي أخفى خلفها الثاعر الكثير من الرموز والإيحاءات التتخيصية، فقد اسقط الثاعر الظروف والفرح والحزن والآلام الحسية والمعنوية الني عاصرها في حياته

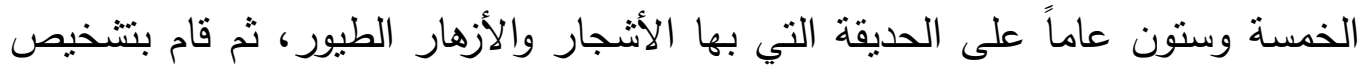

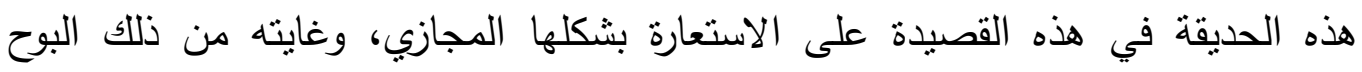

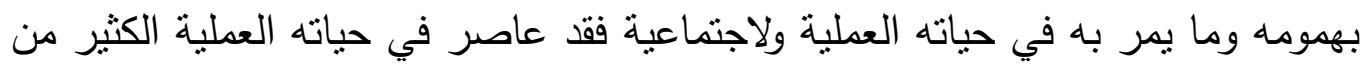
المناصب الكفيلة بعصف ذهنه ونفسيته للبحث عن متتفس لها، فله العديد من القصائد

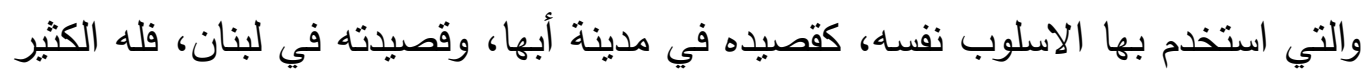
من الإسقاطات الرمزية والتي كان بتخذ من التتخيص لباساً لها فيجعل الجماد حياً ناطقا. وحديقة الغروب شرحت لنا الكثير مما يعاني منه الثاعر فخاطب الحديقة واستعاراتها

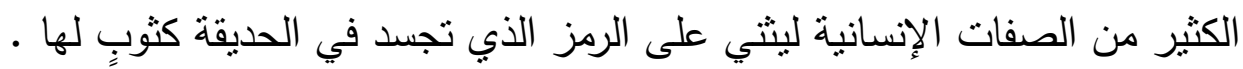

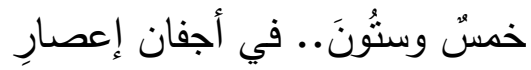

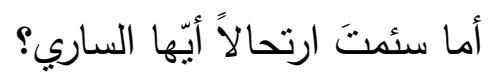

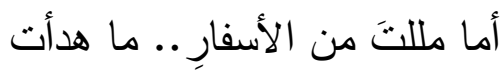

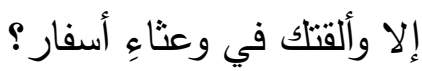

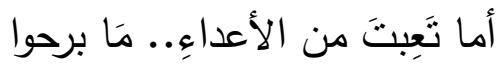
يحاورونكَ بالكبريتِ والنارِ والصحبُ؟ أين رفاقُ العمرِ؟ هل بقِيَتَّ

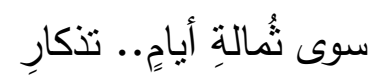

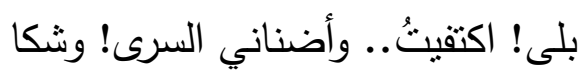

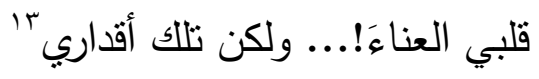

*** *

r" - ديوان حديقة الغروب، القصيبي، غازي عبد الرحمن، ص rا ـ . 


\section{الجمعية المصرية للقر اءة والمعرفة عضو الجمعية الدولية للمعرفة ILA}

يصف الثاعر في مقطوعته الأولى آلامه وأحزانه بعد أن تجاوز عمرة خمس وستون سنة فيها الظروف والمعاناة التي مر بها في حياته، ليمهد الطريق لذكر الظروف الصعبة والمحن العصيبة، فيسقطها على الحديقة في قصيدة التي أسمها (بحديقة الغروب) واختار لها زمن الغروب؛ فهذا الغروب دلالة على أن لكل بداية نهاية، يبدأ الإنسان مراجعة نفسه فيها، فهذا الغروب في الحديقة ارتبط بجلوس الثاعر في أحضانها لمراجعة نفسه من وقت لت بهن الثروق الذي يرمز لبداية معاصرته للحياة وفتوة شبابه، حتى الغروب الذي يجلس فيه الثخص مع نفسه فيرتمى في أحضان هذه الحديقة وقت الغروب وبيدأ بصف مدى حبه لتهن لهذه الحديقة التي يرمي فيها همومه، وأوجاعه وهي تحتويها وتتحملها، بل وتواسيه في همومه. وتقول الثاعرة نازلك الملائكة في لحظة الغروب : 


\section{الجمعية المصرية للقر اعة و المعرفة عضو الجمعية الدولية للمعرفة}

$$
\begin{aligned}
& \text { أيّ معنى هاج في نفسي الغروب } \\
& \text { أجلت في جسدي منه الحياة } \\
& \text { وسرى في مسمعي همس غريب } \\
& \text { كلّه هول ورعب وشكاة } \\
& \text { واعتراني خاطر مشتج رهيب } \\
& \text { وتجلّى لخيالاتي الممات ؛ُ ـأ. }
\end{aligned}
$$

لحظة الغروب هذه هي اللحظة التي بدأ فيها الجماد حياً ناطقا، هي اللحظة التي بدأ فيها

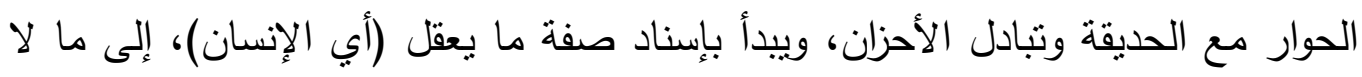

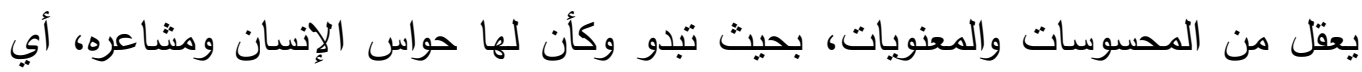
يخاطب ما لا يعقل بخطاب من بعقل مُ ال.

$$
\text { أيا رفيقةَ دربي!... لو لديّ سوى } 17
$$

و بدأ الثاعر التثخيص للحديقة، فيحاور الحديقة وكأن تلك الأثجار والأزهار الأعمدة والإنارة والكراسي التي في الحيقة تعي، وتسمع ما يقوله وهي ظاهرة (تتخصية

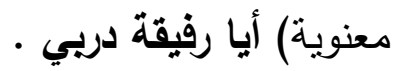

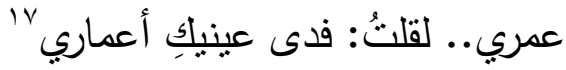

فجعل للحيقة عينان يفداهما بعمره، (فدى عينيك)، وقد تغنى الثعراء كثيراً بالعيون كونها أول ما يراه العانشق من معشوقته وهي ظاهرة (تتخيصية حسية)، فالعين

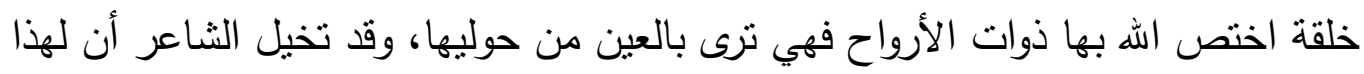

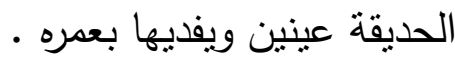

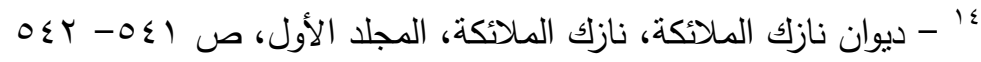

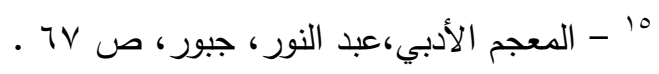

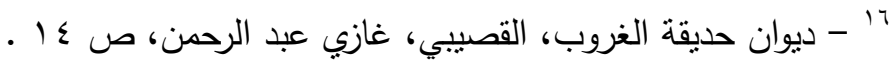

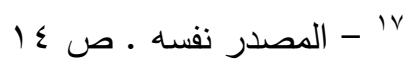




\section{ILA الجمعية المصرية للقر اءة والمعرفة عضو الجمعية الدولية للمعرفة}

$$
\text { أحبيتني... وشبابي في فتوّتهِهُ1 }
$$

واستدرج ظاهرة تشخيصية جديدة وهي (المعنوية) فاقترن التشخيص بلفظة

(أحبيتني) فالحب لا يرى ولا بلمس ولكن، شعور يمكن الإحساس به نفسياً، فالثاعر بينه وبين هذه الحديقة عشرة عمر طويلة، امدته فيها بالراحة والاحتواء، يمكن استتباطها من خلال قوله (وشبابي في فتوته). 


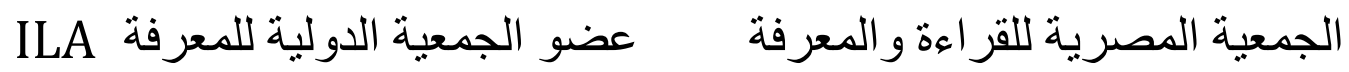

\section{وما تغيرّتِ .. والأوجاعُ سُمّْاري

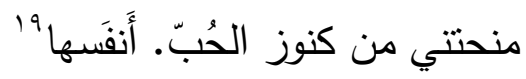

وهنا ظاهرة تشخيصية معنوية، جسَّدها الثاعر لهذه الحديقة حيث لديها قوة

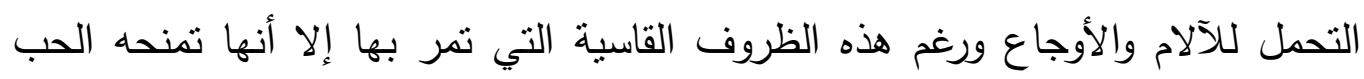
وليس أي حب كذلك بل أنفس أنواع الحب، وهو تبادل شخوصي معنوي، بهذه الحديقة التي أحبت الثشاعر بأغلى وأثنن كنوز الحب، فهي تفرق بين أنواع الحب وتتخير أنفسه (منحتني من كنوز الحب أنْفَسها).

$$
\begin{aligned}
& \text { وكنتُ لولا ندالكِ الجائحَ العاري } \\
& \text { ماذا أقولُ وددثُ البحرَ قافيتي }
\end{aligned}
$$

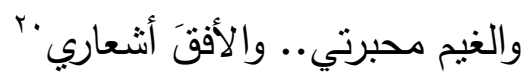

وهذا الفنان المبدع الذي رغب أن ينهج في هذا الطريق الرمزي، ويتخذ من التشخيص ولندي طائراً ليحلق به في سماء الوصف فقد تفنن به أنظر الى هذه الصفة الحسية والمعنوية التي وصف بها هذه الحديقة (وكنت لولا نداك الجائع العاري) فهي يشخصها بصفة التكلم فهي تتاديه وتتبعه ، وتكسيه بأوراقها من العراء، فهي تدرك احتياجه وهي صفة لا بدركها حتى بعض البشر ومن ثم تلبي احتياجه، فقد أبدع الثاعر غازي القصيبي في استخدامه

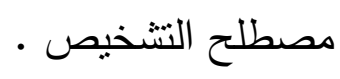

$$
\begin{aligned}
& \text { إنْ ساعلولِ فقولي: " كان يعشقتي } \\
& \text { بكلِّ ما فيهِه من عُنفٍ .. وإصرار } \\
& \text { وكان يأوي إلى قلبي.. ويسكنه } \\
& \text { وكان يحمل في أضلاعهِ داري " }
\end{aligned}
$$

$$
\begin{aligned}
& 19 \text { - المصدر نفسه، ص } 10 .
\end{aligned}
$$

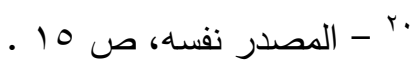




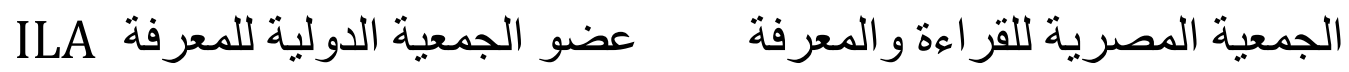

\section{وإِنْ مضيثُ.. فقولي:" لم يكن بَطَكًا

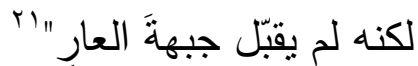

الثناعر عاش ذلك الثتعور - التتخيصي للحديقة - وشاركه مع المجتمع بشكليه الحسي والمعنوي فإذا هو يقول للحديقة (إن ساءلوك) على أن ظاهرة الاستتطاق للجماد

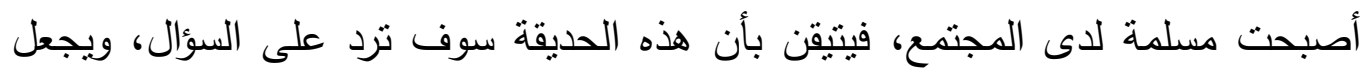

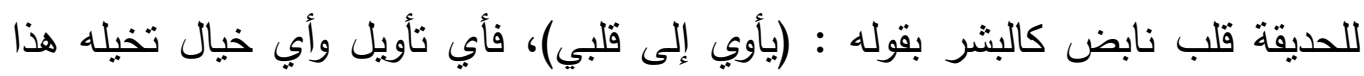

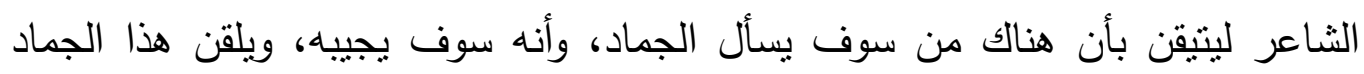
الإجابة ليرد على السائل ليصف نفسه بأنه كان عنيف معها ولم يكن يعاملها بلطف،

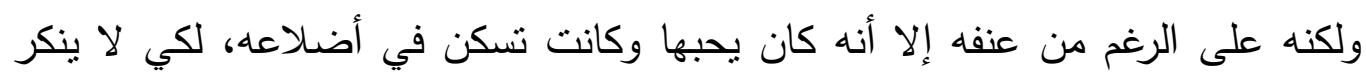

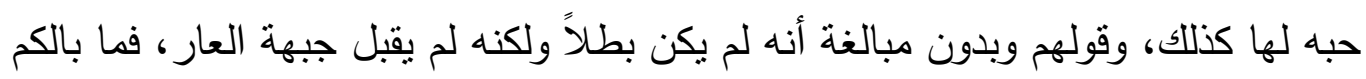

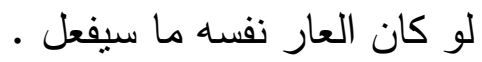

$$
\begin{aligned}
& \text { *** } * \\
& \text { وأنتِ!... يا بنت فجرٍ في تتفّسه } \\
& \text { ما في الأنوثةثة. من سحرِ وأسرارِ } \\
& \text { ماذا تريدين مني؟! إنَّي شَبَحِّ }
\end{aligned}
$$

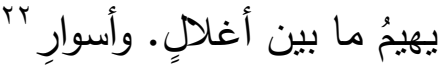

ويحاور الحديقة مرة أخري بأوصاف نتخيصية متتالية ؛ فيشبه الحديقة في أنثاء

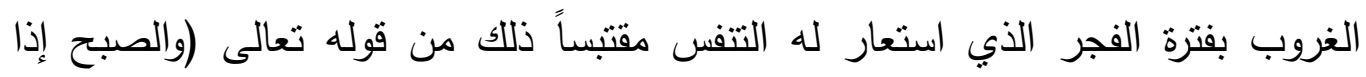

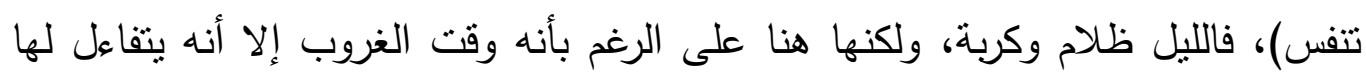

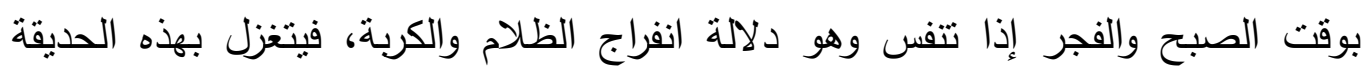

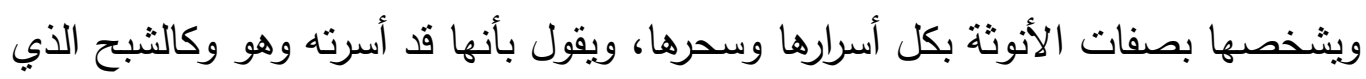

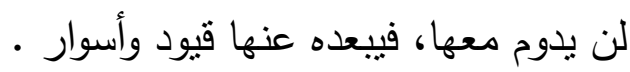

$$
\text { rr }
$$




\section{ILA الجمعية المصرية للقر اعة والمعرفة عضو الجمعية الدولية للمعرفة}

$$
\begin{aligned}
& \text { هذي حديقة عمري في الغروب.. كما } \\
& \text { رأيتِِ... مرعى خريفٍ جائعِ ضارِ }
\end{aligned}
$$

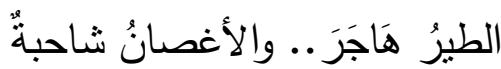

$$
\begin{aligned}
& \text { والوردُ أطرقَ يبكي عهد ..آذارِ } \\
& \text { لا تتبعيني! دعيني!.. واقرئي كتبي } \\
& \text { فبين أوراقِها تلقالكِ أخباري } \\
& \text { وإنْ مضيتُ.. فقولي: لم يكن بطلاً }
\end{aligned}
$$

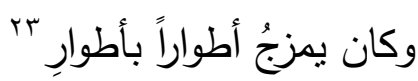

ينتقل من مرحلة لأخرى في وصف هذا الحديقة التي كبرت وتغيرت معالمها، وكأنه يصف بها أجمل مراحل حياته بعد أن كبر سنه (حديقة عمري)، تغير بها الحال

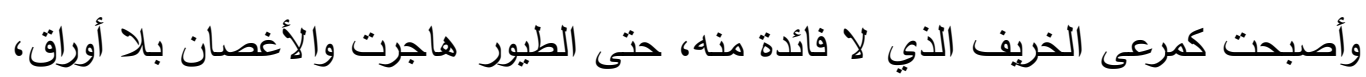
وقد شخصها بالثحوب (والأغصانُ شاحبةٌ) وهي صفة اختصت بالإنسان عندما يكبر وتتغير ملامح وجها، والورود والأزهار التي كانت تخرج في شهر آذر لم تعد كما هي في لخهان الخريف، فشخصها بالبكاء (والوردُ أطرقَ يبكي) وهي صفة حسية تختص بالإنسان، ولم يبق له من أخباره وبطولاته إلا ما دونه وكتبه في أوراقه، ويطلب من الحديقة ألا تتبعه وهي صفة حسية اختص بها ذوات الأرواح التي تمشي وتتحرك (لا تتبعيني! دعيني) و يخبرها إن أرادت أخباره أن تقرأ كتبه، فيشخصها بالقراءة وهي صفة إنسانية (واقرئي كتبي)، ويعود ويحاور الحديقة مرة أخرى ويقول إن سألك عني أحد فقولي: لـ يكن بطلاً بل يمزج أطوار بأطوار متتالية، كان يجبر ظروفه العصيبة بعضها ببعض، فقد خلط شهر فصل الخريف بالعربي ويقابله بشهر آذر في الميلادية، وهذا مزج بين أطوار وأطوار .

$$
\text { *** }
$$$$
\text { ويا بلاداً نذرت العمر .. زَهرتَه }
$$

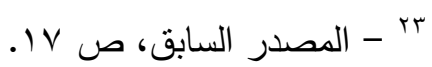




\section{ILA الجمعية المصرية للقر اعة والمعرفة عضو الجمعية الدولية للمعرفة}

$$
\begin{aligned}
& \text { لعزّها!... دُمتِّ!... إني حان إبحاري } \\
& \text { تركتُ بين رمال البيد أغنيتي } \\
& \text { وعند شاطئلِ المسحوٍِ ـ أسماري } \\
& \text { إن ساءلوكِ فقولي: لم أبحْ قلمي } \\
& \text { ولم أدنّس بسوق الزيف أفكاري } \\
& \text { وإن مضيثُ.. فقولي: لم يكن بَطَلاً }
\end{aligned}
$$

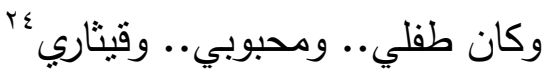

يشخص البلاد أثناء تخاطبه معها و الحوار (بتتخيص حسي) بينه وبينها حين قال

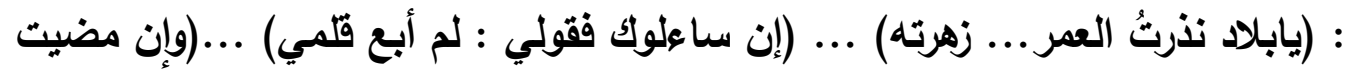
فقولي : لم يكن بطلاً). ويلقنها بصفات حسية أخرى حين جعل نفسه أبنناً ومحبوباً وقيثاراً

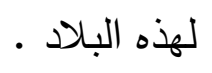

\section{*** $*$}

$$
\begin{aligned}
& \text { يا عالم الغيبٍ! ذنبي أنتَ تعرفُه } \\
& \text { وأنت تعلمُ إعلاني.. وإسراري } \\
& \text { وأنتَ أدرى بإيمانٍ مننتَ به إعله } \\
& \text { علي.. ما خشته كل أوزاري }
\end{aligned}
$$

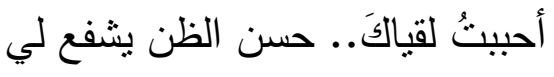

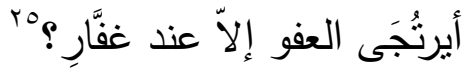

ويختتم الثاعر قصيدته باعترافه بذنوبه وخطاياه، ويطلب العفو والدغفرة من الله

$$
\text { عز وجل، وقد جرى هذا الأسلوب الثعراء. }
$$

$$
\begin{aligned}
& \text { \& } \\
& \text { ro - المصدر السابق، ص } 11 \text {. } 1 \text {. }
\end{aligned}
$$




\section{ILA الجمعية المصرية للقراءة والمعرفة عضو الجمعية الدولية للمعرفة}

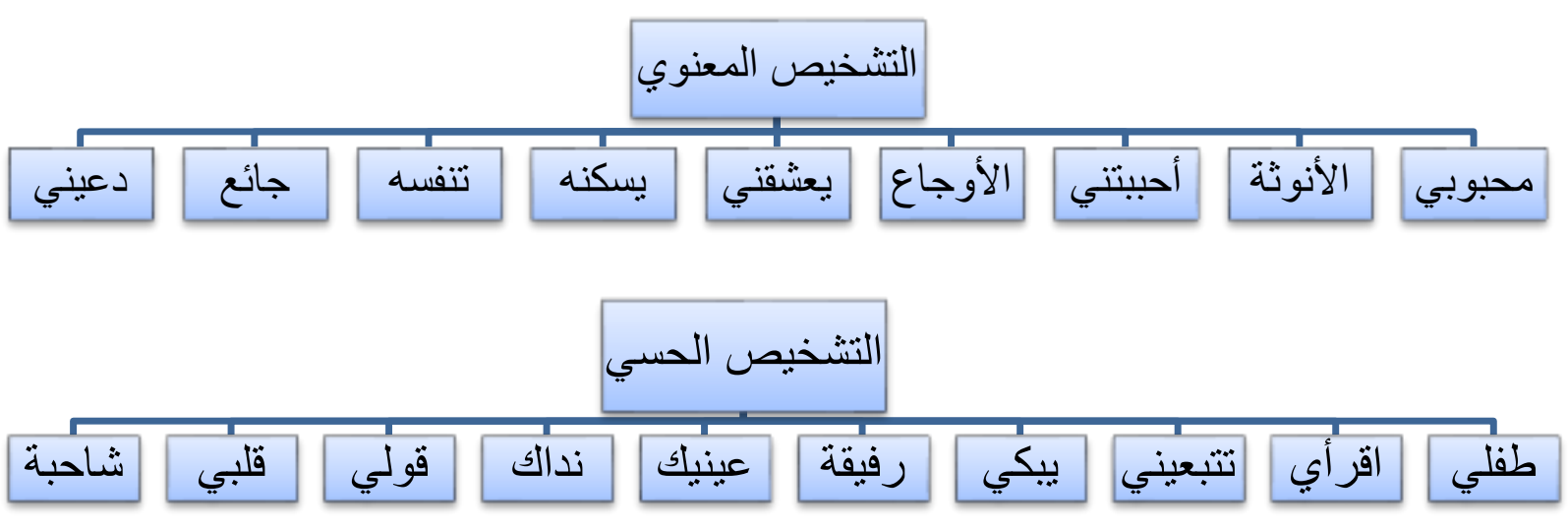

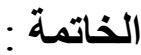

تمت هذه الدراسة بفضل من الله ومنته وقد خلص الباحث إلى عدة نتائج وهي كالتالي :

ا ـ ظاهرة التشخيص وبغض النظر عن مسمياتها العربية و الغربية كانت ظاهرة عند الكثير من المبدعين الأدباء و الثعر اء العرب عامةً، و السعوديين خاصة. ץ- أن العلماء و النقاد العرب لهم السبق في مثل هذه المصطلحات و إن اختلفو ا في المسميات الأدبية إلا أن لهم السبق في الكثير من الظاهر الأدبية وليس التشخيص فقط بل هنالك الكثير من الظواهر الأدبية الي تستحق الدراسة كالتناص، والانزياح، و التوازي، و التلقي ....إلخ . "ـ كان ظهور النشخيص في العمل الأدبي يعطي النص حيوية أكبر، تتيح للناقد، و الباحث البحث لما وراء النص، وكانت قصيدة (حديقة الغروب) خير مثال 


\section{الجمعية المصرية للقر اءة والمعرفة عضو الجمعية الدولية للمعرفة}

عـ الثناعر غازي القصيبي كان يتمتع بحسن استخدامه لهذا المصلح سواء علمه أو جهله، فملكته الشعرية ساعدته وبصورة جلية من خلال هذه الدراسة التي

$$
\text { بينت لنا هذا الابداع. }
$$

0ـ كثر استخدام التشخيص الحسي .والمعنوي، لدى الثشاعر وبشكل ومتقارب

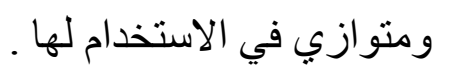

7- أسقط الثاعر ألامه و أحز انه على تللك الحديقة التي تناجيه وتو اسيه وتحتضنه

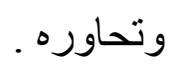

Vـ الأدب السعودي غني بمثل هذا الظاهر الأدبية، وأوصي نفسي وكل باحث

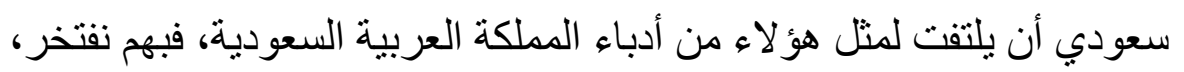
و على كل باحث أن يساهم في مثل ذللك، ولا ضير أن يتم توسيع دائرة البحث بعد أن ننتهي من در اسة أدبائنا أن ندرس أدباء العالم المجاور. ᄉـ تر اثنا الأدبي يستحق منا التمعن و الدراسة ومواكبة الأحداث الأدبية، وبروح تراثية يتم فيها بعث الروح لها من خلال الحفر، والتنقيب في ثناياها، ثم المزواجة بينهاوبين الحاضر ، لنخرج بو لادة جديدة في أدبنا العربي المعاصر. 


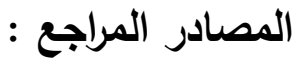

1- أسرار البلاغة، الجرجاني، عبدالقاهر، تحقيق : السيد محمد رشيد رضا، بيروت : دار المعرفة،

$$
\text { . } 19 \vee \wedge
$$

r- - ثقافة الناقد الأدبي، النويهي، محمد، ط ل، القاهرة، مطلعة لجنة التأليف والتزجمة والنشر،

$$
\text { . } 19 \leq 9
$$

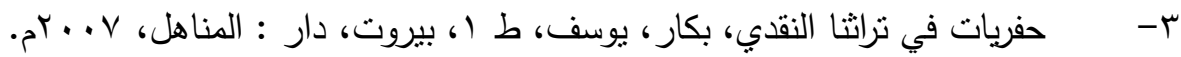

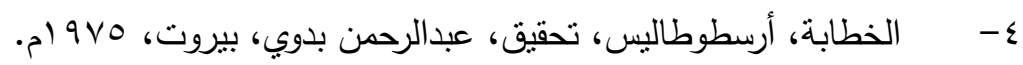

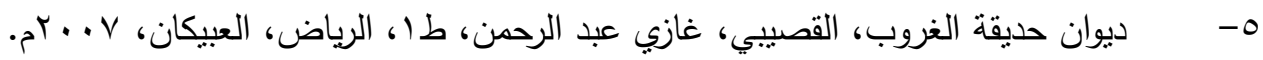

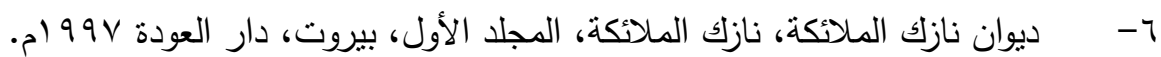

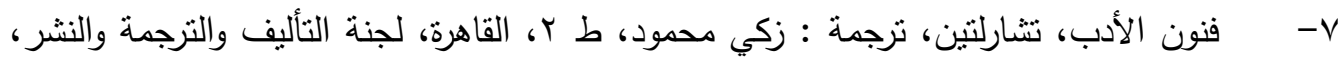

$$
.1909
$$

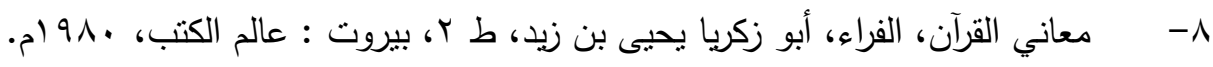

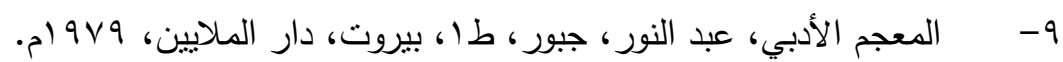

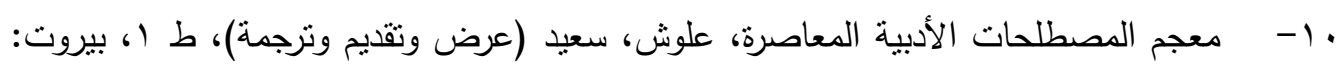
دار الكتاب اللبناني، 910 ام.

11- مجم لسان العرب، ابن منظور، تحقيق عبد الله الكبير و محمد أحمد حسب الله وهاشم

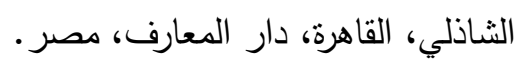

r ب- القد الثعر قدامة بن جعفر، تحقيق : محمد عبد المنعم خفاجي، بيروت : دار الكتب العلمية.

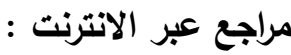

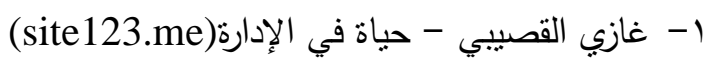
ץ- ما لا تعرفه عن غازي القصيبي .. من هو ؟ سيرته الذاتية، إنجازاته وأقواله، معلومات عن غازي القصيبي(arageek.com) 